\title{
O Pragmatismo do Petróleo: as relações entre o Brasil e o Iraque
}

\author{
The oil pragmatism: the Brazil-Iraq relations
}

SEME TALEB FARES*

Rev. Bras. Polít. Int. 50 (2): 129-145 [2007]

\section{Introdução}

A história das relações entre o Brasil e o Iraque, à primeira vista, aparenta inexpressiva, de importância bastante reduzida para a política externa brasileira. Observando os interesses que o governo brasileiro detém no Iraque hoje, essa impressão parece confirmada, afinal. No entanto, uma análise mais detida da história do relacionamento entre os dois países revela um cenário bastante diverso. Sem se pretender superdimensionar a importância do Iraque para o Brasil, argumenta-se neste artigo que o Iraque não foi um parceiro tão irrelevante ao País como um rápido julgamento pode supor ${ }^{1}$.

O relacionamento brasileiro-iraquiano foi influenciado, em grande medida, por interesses de ordem econômica, que sofreu, desde o início da década de 1970 até os dias de hoje, constrangimentos domésticos e, principalmente, estruturais. Como se não bastasse, juntamente com os interesses comerciais, um importante elemento estratégico no relacionamento bilateral foi observado, criado pela: i) exportação de materiais bélicos, que, ao lado da simples obtenção de lucros, tinha um objetivo de segurança nacional ao Brasil; e ii) sensível área de cooperação nuclear, provavelmente com objetivos militares.

Nesse sentido, este artigo traça - em termos bastante gerais - os principais movimentos da história das relações Brasil-Iraque, desde 1973 até 2007. Para tanto, são analisados os fatores que conduziram a uma maior aproximação comercial entre os dois países, assim como suas implicaçōes políticas na agenda de discussão bilateral. Em seguida, são apresentados os desdobramentos estratégicos desse relacionamento, em especial no campo da venda de armas e na cooperação nuclear. Por fim, são identificados os constrangimentos domésticos e, principalmente, estruturais que ceterminaram o ceclínio dessas relaçóes até um ponto de real ruptura.

\footnotetext{
* Mestre em Relações Internacionais pela Universidade de Brasília - UnB (seme.fares@gmail.com).

1 Este artigo é extensivamente baseado na dissertação de mestrado do autor, apresentada em 2007 ao programa de pós-graduação em Relações Internacionais da Universidade de Brasília - UnB, intitulada O pragmatismo do petróleo: as relaçôes entre o Brasil e o Iraque, de 1973 a 2007.
} 


\section{Considerações iniciais}

Até 1973, o Oriente Médio significava uma área pouco atrativa na ótica da política externa brasileira, cujo relacionamento era marcado por contatos episódicos. ${ }^{2}$ Em outros termos, dentro da lógica do pragmatismo e da diplomacia econômica adotados pelo Itamaraty, os países do Oriente Médio, inclusive o Iraque, representavam peça demasiadamente marginal no cenário das relações internacionais.

Somente com a crise ocasionada com o aumento vertiginoso do preço do barril do petróleo (que passou de US\$ 3 para US\$ 12), após a Guerra do Yom Kippur/Guerra de Outubro, essa postura da diplomacia brasileira iria sofrer uma inflexão. Ao lado disso, com o aumento no preço do barril do petróleo, o governo iraquiano tinha dinheiro e determinação suficientes para investir em infra-estrutura com vistas ao projeto de modernização do país e fazer pesados investimentos militares. ${ }^{3}$ Do ponto de vista financeiro, o país passava a faturar mais que o triplo em 1973 quando comparado ao ano anterior. Em 1974 esse número havia se multiplicado em cerca de dez e, em 1980 (ano de maior pico nas receitas com o petróleo), em cinqüenta, tendo como base ainda 1972. Tudo isso teve repercussões claras na política externa iraquiana. ${ }^{4}$

As relaçóes brasileiro-iraquianas remontam ao ano de 1947, quando os dois países estabeleceram oficialmente laços diplomáticos. Mas é somente a partir do início da década de 1970, antes mesmo do choque do petróleo, que elas iriam ganhar densidade e maior atenção de ambos os países, até porque o baixo nível de desenvolvimento econômico do Iraque de antes limitava seriamente a sua interação bilateral com o Brasil. O primeiro importante acordo de comércio entre os dois países foi firmado em 1971. É importante frisar que a conclusão de tratados pelo Iraque com outros países não era fato corriqueiro nessa época. Explica-se: considerado como um Estado altamente revisionista, e que tinha como inimigos declarados o imperialismo e o sionismo, a Europa Ocidental e os EUA reagiam de modo a isolar o Iraque no contexto internacional. Diante disso, o Brasil detinha uma excelente oportunidade para aprofundar o seu relacionamento comercial com um importante exportador de petróleo. ${ }^{5}$ Se do lado iraquiano a questão do custo político com o risco de um isolamento era tida como uma das mais importantes no que se referia às suas relaçōes comerciais, isso se tornou conveniente para o Brasil expandir o seu comércio exterior.

2 VIZENTINI, Paulo G. F. A Politica Externa do Regime Militar Brasileiro: multilateralização, desenvolvimento e a construção de uma potência média (1964-1985). Porto Alegre: Ed. da Universidade, 1998. p. 245.

3 MENDES, Murillo e ATTUCH, Leonardo. Quebra de Contrato: o pesadelo dos brasileiros. São Paulo: Del Rey, 2004. p. 156.

4 DESSOUKI, Ali E. Hillal e KORANY, Bahgat. The Foreign Policies of Arab States: The Challenge of Change. Boulder, Colorado: Westview Press, 1991. pp. 192 e 193.

5 SAKAI, Keiko. Japan-Iraq relations: the perception gap and its influence on diplomatic policies. Arab Studies Quartely. Fall 2001; 23, 4. p. 121. 
O governo brasileiro e, principalmente, a Petrobras sob a administração de Ernesto Geisel (antes mesmo de se tornar Presidente da República, portanto), tinham consciência de que o País dependeria do petróleo importado por um longo tempo ainda. Pelo menos no início da década de 70, o alcance da autosuficiência na produção nacional de petróleo era visto como algo improvável. Isso porque o consumo de petróleo no País crescia na ordem de 7\%, enquanto a produção não atingia sequer um crescimento de $5 \%{ }^{6}$

A par disso, o Brasil iria quadruplicar seus gastos com a importação de petróleo em 1974 quando comparado ao ano anterior. ${ }^{7}$ A economia brasileira, na realidade, estava cada vez mais dependente da importação de petróleo. Em 1974, o Brasil era o maior importador de petróleo entre os países em desenvolvimento e o sétimo em escala mundial, sendo necessários cerca de $40 \%$ das exportações brasileiras para pagar a importação somente desse produto. ${ }^{8}$ A atenção, então, voltar-se-ia ao Oriente Médio, "por causa do suprimento de petróleo e do mercado para os nossos produtos". " Nesse momento, o petróleo figuraria como tema primordial da política externa brasileira e do programa de desenvolvimento econômico do País, que continuavam imbricados. De uma importância risível, o Iraque, com o seu petróleo, se tornaria essencial para a economia brasileira. ${ }^{10}$

\section{Exportação de bens e serviços brasileiros para o Iraque}

Com o novo cenário criado pela primeira crise do petróleo, o Iraque vinha sendo considerado um dos melhores mercados do mundo árabe pelo governo brasileiro. Como era de se esperar, não havia uma política única para todos os países do Oriente Médio. A “opção iraquiana” parecia, desde o princípio, se não a melhor alternativa para o Brasil entre os produtores de petróleo, aquela com excelentes perspectivas para o futuro. A ação diplomática brasileira tornou-se próativa em relação ao Iraque. Afinal, o país necessitava importar praticamente tudo, de alimentos a manufaturados e, ao mesmo tempo, era grande exportador de petróleo, produto do qual o Brasil dependia. Em 1977, por exemplo, o Iraque foi o terceiro maior parceiro comercial do Brasil, atrás apenas dos EUA e da Arábia Saudita. O problema é que esse valor era quase que totalmente representado pelas importações brasileiras de petróleo. Era preciso, pois, reverter essa situação ou,

6 Monopólio não é um fim, mas apenas meio de ação. Estado de São Paulo. 30/07/1970.

7 VELLOSO, João Paulo dos Reis. O Último Trem para Paris: De Getúlio a Sarney: "milagres", choques e crises do Brasil moderno. Rio de Janeiro: Nova Fronteira, 1986. pp. 202, 219 e 226.

8 SANTOS, Norma Breda dos. (Org.). Brasil e Israel: Diplomacia e Sociedades. Brasília: Ed.UnB, 2000. p. 56.

9 Ernesto Geisel. In: D’ARAÚJO, Maria Celina e CASTRO, Celso. Ernesto Geisel: depoimentos. Rio de Janeiro: Fundação Getúlio Vargas, 1997. p. 338.

10 Projeto aliou reserva de mercado e estatização. Estado de São Paulo. 14/09/1996. Geisel visita o Paraná. Estado de São Paulo. 13/06/1973. Braspetro, a maior realização. Estado de São Paulo. 10/07/1973. Ficará para Geisel o desafio do petróleo. Estado de São Paulo. 11/12/1973. FAUSTO, Boris. História Concisa do Brasil. São Paulo: Editora da Universidade de São Paulo, 2006. p. 270. VIZENTINI, Paulo G. F. Op. cit. p. 202. SKIDMORE, Thomas. Brasil: de Castelo a Tancredo (1964-1985). Rio de Janeiro: Paz e Terra, 1988. p. 315. 
ao menos, diminuir o déficit contra o Brasil no seu comércio com o Iraque. Do projeto de desenvolvimento econômico do Brasil, com ênfase na exportação, fazia parte sua parceria com o Iraque. ${ }^{11}$

Apesar das dificuldades, quando comparado a outros países da região, o Iraque era o que mais espaço não explorado em seu mercado oferecia para o Brasil. Outros países produtores de petróleo já tinham a maior parcela de seus mercados dominados por empresas estrangeiras. Ao Irã, por exemplo, o Brasil interessava muito pouco. Isso, combinado com a característica do governo iraquiano em preferir formar um maior leque de fornecedores estrangeiros para não correr o risco político de depender de apenas uma ou poucas fontes, foi o fator que mais contribuiu para a entrada do Brasil no mercado iraquiano.

Nesse sentido, um dos negócios de firmas brasileiras que mais se sobressaiu no ramo da construção civil dizia respeito à ferrovia que ligava as cidades iraquianas de Bagdá e Akashat. As obras da ferrovia, a cargo da Mendes Jr., foram orçadas em 1,2 bilhão de dólares. Tal contrato, além de ter sido o maior já firmado por uma empresa brasileira no exterior, representava etapa decisiva no relacionamento entre Brasil e Iraque. Iniciadas em setembro de 78, as obras foram entregues ao governo iraquiano dentro do prazo estabelecido, em $1983 .{ }^{12}$

O contrato da ferrovia, assim como a maioria dos empreendimentos comerciais entre o Brasil e o Iraque, contou durante todo o tempo com a supervisão e interferência do governo brasileiro a fim de vê-lo bem sucedido. Inseria-se, portanto, dentro da regra geral dos negócios entre os dois países. A exportação de serviços de engenharia civil pelo Brasil ao Iraque se configuraria como um dos ramos mais proeminentes do relacionamento bilateral e também o de maior potencialidade. A dinamização desse setor seria prejudicada somente por acontecimentos exógenos à própria lógica do relacionamento, qual seja, o envolvimento do Iraque em operaçóes de guerra, que consumia os recursos antes dedicados às obras de infra-estrutura e prejudicava os andamentos dos trabalhos. Além das exportações de serviços, o Brasil exportou principalmente bens manufaturados ao Iraque, como veículos, principalmente nos primeiros anos da década de 1980. Isso ocorria em um período bastante providencial para diversas indústrias brasileiras, considerando a situação de estagflação doméstica.

Para contornar os obstáculos advindos da escassez de divisas estrangeiras enfrentadas pelo Brasil, foi utilizada em parte expressiva das trocas comerciais com o Iraque, inclusive na venda de serviços, uma modalidade de comércio compensado (sistema barter ou counter-trade), desde o início da década de $1970 .{ }^{13}$ Para tanto,

11 Entrevista concedida ao autor por Paulo Tarso Flecha de Lima, em 16 de março de 2007, em Brasília.

12 Brasil consolida suas relações com o Iraque. O Globo. 18/12/1979. O trabalho dos brasileiros no Iraque. Estado de São Paulo.12/10/1980. Ofensiva brasileira no Oriente: começa com venda de armas e construção de uma estrada no Iraque. Correio Braziliense. 10/11/1977. BRASIL. Ministério das Relaçōes Exteriores. Relatório. 1978. VIZENTINI, Paulo G. F. Op. cit. p. 249. MENDES, Murillo e ATTUCH, Leonardo. Op. cit. p. 170.

13 Arquivo Histórico do Itamaraty (AHI), Brasília, Embaixada em Bagdá para Secretaria de Estado, n. 90. Confidencial. Em 26/07/1976. 
era empregada a conta petrolífera da Petrobras como meio de financiamento das exportaçóes brasileiras. Por meio desse instrumento, pelo menos em parte, a compra de petróleo seria paga com as exportaçôes de mercadorias e serviços brasileiros. Em meados da década de 1980, não só autoridades do governo, como também setores expressivos da sociedade brasileira consideravam as relações brasileiro-iraquianas uma das mais bem-sucedidas operaçōes diplomáticas e comerciais já empreendidas pelo Brasil. Enfim, "um exemplar casamento entre iniciativas do Itamaraty e do empresariado". ${ }^{14}$

De qualquer modo, os déficits em conta corrente para o Brasil no comércio com o Iraque eram uma constante. Do lado das compras brasileiras provenientes do Iraque, só em 1980, cerca de 40\% do total de petróleo importado pelo Brasil eram daquele país. A participação do Iraque no total das importações brasileiras era alta, chegando, em 1980, a representar mais de 16\%. Ao contrário, o percentual das exportações destinadas ao Iraque continuava baixo, não alcançando sequer os 3 pontos percentuais do total exportado pelo Brasil. Muito provavelmente, os obstáculos maiores para que o Brasil diminuísse seus déficits com o Iraque eram: i) o custo do transporte, que elevava significativamente os preços finais dos produtos brasileiros; ii) o relativamente pequeno desenvolvimento industrial e financeiro do País quando comparado a França, EUA e Japão.

É verdade que no caso iraquiano as preferências recaiam não somente sobre os produtos mais bem qualificados e com preços competitivos, como também de acordo com a sua nacionalidade. Afinal, era preciso tratar de assuntos políticos para vender aos iraquianos. Os critérios políticos e econômicos estavam confusamente imbricados do lado iraquiano. Por certo, a densidade das relaçōes comerciais leva, no mais das vezes, à consolidação das relações diplomáticas e políticas. No caso do Iraque, o caminho que levaria do econômico para o político foi substancialmente encurtado pela própria lógica de relacionamento do país.

As relações do Brasil com o Iraque na área comercial, tomados os anos da década de 70, 80 e início da de 90, evidenciam um planejamento sistemático e de prazo dilatado para a atuação do País no mercado iraquiano. A oportunidade comercial que o Iraque representava e a ligação das exportações de bens e serviços brasileiros com a compra de petróleo foram campo propício para a atuação do serviço de promoção comercial do Itamaraty, da Petrobras, da Presidência da República e de outros ministérios, como da indústria e de minas e energia. De fato, a expectativa do Brasil de que o Iraque continuaria oferecendo oportunidades para novas inversões em seus programas de reconstrução no pós-guerra Irã-Iraque (1980-1988) não se confirmou, com um final abrupto da sociedade causado pela invasão do Kuwait pelo Iraque em 2 de agosto de $1990 .{ }^{15}$ Mas isso, por si só, de

14 O Brasil no deserto: doze anos depois do primeiro lance da Petrobras, já são 6.000 os brasileiros na rota de Bagdá. Veja. 04/12/1985.

15 MONTENEGRO, Marcelo Luis. Indústria Bélica e Diplomacia na Relação Brasil-Iraque (1979-1989): crise de uma estratégia de política externa brasileira para os anos 80. Dissertação (Mestrado em Relações Internacionais). PUC-Rio, 1992. pp. 130, 164 e 166. 
maneira alguma evidencia que os cálculos do Brasil foram errados por não terem conseguido antecipar uma movimentação militar do Iraque, seu enfraquecimento econômico e conseqüente instabilidade política. As expectativas, à época, eram realistas e havia grande interesse comercial no Iraque não só por parte do Brasil, como também de várias outras nações. Salvo melhor juízo, é invariavelmente inerente ao relacionamento com os países do Oriente Médio, em grande medida, correr riscos políticos em decorrência de aventuras militares ou distúrbios sociais. Disso, nem mesmo os "países centrais" estavam imunes.

\section{Implicações políticas do relacionamento bilateral brasileiro-iraquiano}

A crise do petróleo surtiu efeitos no Brasil não só no campo econômico, mas também no campo político. Isso porque os países árabes produtores de petróleo, como o Iraque, tentavam deixar claro ao governo brasileiro que principalmente pelas relaçóes políticas é que o comércio ficaria garantido. Desse modo, a despeito de uma resistência do Itamaraty, que preferia concentrar a agenda bilateral em assuntos econômicos, os interesses árabes eram principalmente políticos. Não havia uma dissociação clara entre economia e política. ${ }^{16}$ A excelência do relacionamento dependia, portanto, de encontrar a interseção entre os dois lados. Em poucas palavras, os interesses brasileiros, se não de modo geral, pelo menos no que dizia respeito ao Oriente Médio, estavam mais voltados para o campo econômico, com uma postura política apenas reativa às necessidades traçadas pelo campo da economia.

Nesse sentido, a questão palestina, ligada à lógica do pan-arabismo, vinha sendo colocada em debate na agenda de discussão brasileiro-iraquiana. O chanceler Saraiva Guerreiro, em 1979, por exemplo, viu-se obrigado a se defrontar com o chanceler do Iraque - país que fornecia mais da metade de todo o petróleo consumido no Brasil à época - que exigia, sem grandes formalidades, a abertura do escritório em Brasília da Organização para a Libertação da Palestina (OLP). Diante do alto grau de dependência brasileira do petróleo iraquiano, o que seria um pedido político pareceu, para grande número de setores domésticos, mais uma imposição externa. $\mathrm{O}$ governo iraquiano vinha se empenhando em conseguir a autorização do Brasil. O papel de líder na defesa do pan-arabismo no Oriente Médio e no mundo era almejado com perseverança pelo Iraque. Sem embargo, as relações brasileiro-iraquianas influenciaram sensivelmente a postura do Brasil quanto à questão palestina. Tanto no âmbito doméstico como no internacional, a polêmica sobre o reconhecimento da OLP e a instalação de um escritório em

16 Pragmatismo conduz a maior aproximação com os árabes. Estado de São Paulo. 28/12/1979. Braspetro discute com o Governo do Iraque a exploração de seu petróleo. Jornal do Brasil. 03/06/1979. DESSOUKI, Ali E. Hillal e KORANY, Bahgat. Op. cit. p. 202. 
Brasília ganharam amplitude seguramente indesejada pelo Itamaraty. ${ }^{17} \mathrm{O}$ tema palestino, desse modo, vinha contribuindo para diminuir a relativa falta de dinamismo político nas relaçôes Brasil-Iraque.

No fim, as diferenças culturais entre os dois países não foram levadas muito em conta, pecando, a chancelaria brasileira, pelo excesso de simplificação nas suas análises, o que a conduziu a avaliaçóes apressadas. $\mathrm{O}$ excessivo enfoque comercial dado pela Petrobras, que desejava comprar petróleo ao menor preço possível, ao invés de beneficiar, prejudicava os canais diplomáticos e a conseqüente evolução no campo político do relacionamento. O Brasil muito mais reagiu nesse tocante do que propôs ações, que, grosso modo, foram determinadas pelo Iraque.

As relações, que vinham sendo consolidadas na década de 70 , alçariam à posição de maior importância econômica, comercial e com um novo e substancial componente político a partir da década de 80 . As relaçóes Brasil-Iraque eram fortemente condicionadas pela estrutura internacional, desde o princípio da aproximação entre os dois países no início da década de 1970. A segunda crise do petróleo (1979) representaria apenas mais um componente exógeno que influenciaria os rumos desse relacionamento. Nessa época, havia quem defendesse que o Iraque era "o maior aliado do Brasil no momento"18.

\section{O peso do petróleo iraquiano para a economia brasileira}

A questão do petróleo foi uma fundamental influenciadora da política externa brasileira nas décadas de 70 e 80 . O suprimento de petróleo constituiu uma das maiores vulnerabilidades do País e sério empecilho para o seu esforço de crescimento econômico. ${ }^{19}$ Para o setor de transportes e mesmo na indústria, não havia, a curto e médio prazos, sucedâneos para o petróleo importado, principalmente durante o governo Geisel.

O governo de João Figueiredo ainda viveria sob um cenário de desabastecimento e aumento no preço do barril de petróleo, com a eclosão de nova crise em 1979. Diante disso, a questão do suprimento de petróleo havia se transformado em um dos problemas mundiais mais cruciais e que necessitava atenção e tratamento prioritário do governo, na visão do chanceler Saraiva Guerreiro. Naquele ano, cerca de $90 \%$ do petróleo consumido no Brasil era importado.

17 É a hora de mudar de conduta. Estado de São Paulo. 05/06/1979. Política externa do Brasil: novos caminhos para acompanhar a transformação do mundo. O Globo. 29/07/1979. Acerto entre o Brasil e Iraque. Gazeta Mercantil. 18/12/1980. Brasil evita polêmica com visita iraquiana. Jornal de Brasília. 09/12/1979. A lógica do Iraque. Jornal de Brasília. 09/12/1979. "Nada afeta nossa amizade": o embaixador Haidar faz um balanço das relaçōes entre Brasil-Iraque. Folha de São Paulo. 19/03/1980. ATTUCH, Leonardo. Saddam, o Amigo do Brasil. São Paulo: Qualitymark, 2003. p. 136.

18 Brasil entrega Majnoon para ter óleo do Iraque. Jornal do Brasil. 02/12/1979.

19 BRASIL. Ministério das Relaçôes Exteriores. Resenha de Política Exterior do Brasil. Ano III, n. VIII. Geisel: nossa diplomacia é instrumento de progresso e segurança. Mensagem do Presidente da República ao Congresso Nacional, em 1 de março de 1976. 
Após a Revolução Iraniana, também em 1979, a preocupação com a manutenção do fornecimento do petróleo só faria crescer. Durante muito tempo, o Brasil procurou outros produtores de petróleo, mas foi o Iraque o seu principal fornecedor. Somente em 1981, para se ter uma idéia, o Iraque era responsável por cerca de $50 \%$ de todo o óleo consumido no País, sendo o principal fornecedor desde 1979, quando ultrapassou a Arábia Saudita. A verdade é que, ao surgirem deficiências de outros supridores, o Iraque compensava eventuais quedas. Daí o motivo de tamanha concentração, "o que não era sadio, mas, no aperto em que vivíamos, era explicável”. ${ }^{20}$ Caber lembrar que, em 1978, a participação do petróleo nas importações totais brasileiras era de 30\%, saltando para 50\% em 1981 e alcançando 53\% em 1983. Somente em 1985 é que esse percentual decaiu para $43 \%$. Se forem considerados os países do Golfo Pérsico/Arábico, a dependência representava cerca de $90 \%$, o que demonstrava a ineficiência da política de diversificação de fontes supridoras de petróleo. ${ }^{21}$ Para muitos, o Brasil estava "literalmente nas mãos do governo de Saddam Hussein e jamais, por incrível que pareça, esteve tão dependente dos EUA como diante do Iraque". ${ }^{22}$

Das várias alternativas apresentadas ao Brasil após a segunda crise do petróleo e a Revolução Iraniana, o Iraque era a que se mostrava mais viável - talvez a única. A Petrobras havia feito, por exemplo, reiterados pedidos ao governo da Arábia Saudita, assim como da China, no sentido de elevar a quantidade de petróleo fornecida ao Brasil. No entanto, essas tentativas foram frustradas. ${ }^{23}$ Os preços praticados no mercado spot (mercado livre do produto) apresentavam-se extremamente extorsivos e o Brasil, caso não saísse bem sucedido na sua busca por um supridor alternativo ao Irã a preços OPEP, estabelecidos em 21 dólares por barril (o que já era bastante elevado), seria obrigado a recorrer a esse expediente, em que o preço do barril chegava a alcançar a cotação de 48 dólares em fins de 1979. Como se não bastasse, a crise econômica internacional - de mercados, inflação e juros - transformava o segundo choque do petróleo em um acontecimento muito mais grave que o choque de $1973 .^{24}$

20 GUERREIRO, Ramiro Saraiva. Lembranças de um Empregado do Itamaraty. São Paulo: Siciliano, 1992. p. 178.

21 SANTOS, Norma Breda dos. (Org.). Op. cit. pp. 161 e 170.

22 Brasil quer petróleo e o Iraque, tecnologia nuclear. Estado de São Paulo. 09/11/1979.

23 ATTUCH, Leonardo. Op. cit. p. 112. Ministro do Iraque vem dia 11 para negociar petróleo. Jornal do Brasil. 07/12/1979. VIZENTINI, Paulo G. F. Op. cit. pp. 254 e 262.

24 Bons negócios no Iraque. Jornal de Brasília. 24/11/1979. Novas possibilidades de intercâmbio com o Iraque. Gazeta Mercantil. 23/11/1979. O Itamaraty está cuidando dos brasileiros no Iraque. Jornal da Tarde. 24/09/1980. Petrobras conseguiu o petróleo do Iraque. Estado de São Paulo. 24/11/1979. Itamaraty orienta ação no Oriente Médio e Irã. Estado de São Paulo. 24/11/1979. Itamaraty evita política com o ministro do Iraque. Jornal do Brasil. 09/12/1979. BRASIL. Ministério das Relaçōes Exteriores. Resenha de Politica Exterior do Brasil. N. 42, de 1984. A conferência do chanceler Saraiva Guerreiro na Escola Superior de Guerra. Conferência de 31 de agosto de 1984. BRASIL. Ministério das Relações Exteriores. Relatório. 1979. ATTUCH, Leonardo. Op. cit. p. 138. VELLOSO, João Paulo dos Reis. Op. cit. pp. 167 e 170. GUERREIRO, Ramiro Saraiva. Op. cit. p. 177. VIZENTINI, Paulo G. F. Op. cit. p. 338. 
O Iraque, no fim, garantiria o fornecimento de petróleo, a preços oficiais da OPEP, sem cobrar as sobretaxas em vigor no mercado internacional, o que significou um benefício relevante e um alívio à economia brasileira em um momento crítico do mercado petrolífero. Sem o Irã, aumentava a dependência do Brasil em relação ao Iraque. Crescia, portanto, a aproximação do Brasil a uma situação em que dependeria de um grande fornecedor individual, em decorrência das facilidades e da confiabilidade de suprimento e, principalmente, preço. ${ }^{25} \mathrm{O}$ Iraque contribuiu para que o Brasil superasse sem problemas de abastecimento o segundo choque do petróleo, mas também via aumentar sua fatia no mercado brasileiro do hidrocarboneto, agora com cerca de 50\%. Com todos esses eventos que circundaram a crise de 1979, o Iraque se mostrou essencial para a manutenção no fornecimento de petróleo a preços mais baixos que os pagos pela maioria dos países consumidores. Mesmo diante da guerra do Iraque contra o Irã, o país árabe procurou garantir o fornecimento de petróleo ao Brasil, se não diretamente, ao menos através de gestóes junto a outros países produtores de petróleo para entregar ao mercado brasileiro em condições e preços favoráveis.

Apesar da proximidade geográfica com a Venezuela e de seu expressivo quantitativo de petróleo produzido e exportado, o país sul-americano, que era tradicional fornecedor dos EUA, não figurava como um dos primeiros supridores do Brasil. Enquanto que, em 1979, o Iraque era responsável por mais de 40\% do suprimento de petróleo ao Brasil, a Venezuela respondia por apenas 1,7\% do total. Ademais, tendo em vista que, na maior parte das vezes, o Iraque aceitava o pagamento de suas vendas de petróleo por produtos e, quando em moeda, pagamentos diferidos, enquanto a Venezuela exigia o pagamento com moedas internacionais fortes, como o dólar, os negócios com os iraquianos eram sobremaneira facilitados. Se o pragmatismo da política externa brasileira ia além do rótulo para a prática efetiva, isso era mais verdadeiro ainda para a política de compra de petróleo pelo País.

O Brasil, ao que parece, se preocupava menos em depender quase que exclusivamente da importação de petróleo de um único fornecedor internacional, mesmo levando-se em conta todos os custos políticos e riscos para o abastecimento. O mais importante, no caso, era a economia que isso poderia gerar. O componente estratégico e político, diante do econômico, pois, ficava relegado a um segundo plano. O preço estava em primeiro lugar.

A dependência brasileira do petróleo iraquiano, observada principalmente nos últimos anos da década de 1970 e os primeiros da de 1980, ao mesmo tempo, facilitava e tornava mais difíceis outros aspectos do relacionamento bilateral. De um lado, os negócios comerciais e econômicos viam-se bastante facilitados, dado que abria a possibilidade de utilização de instrumentos do tipo barter trade e maior busca pelo Brasil em tentar compensar a grande quantidade de dólares

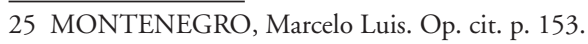


gasta com a compra do produto. Por outro lado, o relacionamento político sofria de uma espécie de tensão permanente, em prejuízo a uma posição mais segura e confortável para o Brasil, uma vez que tamanha dependência significava menor margem de manobra para o País negar esse ou aquele apoio solicitado pelas autoridades iraquianas. Tanto assim que, à medida que a dependência do petróleo do Oriente Médio foi diminuindo, a diplomacia brasileira se tornava menos propensa a cortejar os produtores de petróleo da região.

\section{Aprofundamento estratégico do relacionamento bilateral}

De uma relação eminentemente comercial, por uma mutação das identidades, dos interesses e da percepção de um para o outro, as relações Brasil-Iraque se tornariam também estratégicas. ${ }^{26}$ Esse movimento ocorreu especialmente na área de equipamentos bélicos convencionais e na de cooperação nuclear, o que acarretaria grande custo político ao Brasil, gerando desconfianças por parte dos EUA e um progressivo afastamento das posições de Israel.

No mercado internacional de armas, o Brasil foi um dos poucos países do terceiro mundo que participou ativamente da corrida armamentista, desde meados dos anos 70 até o final da década de 80 . Foi durante essa última década que o Iraque se tornaria o principal cliente da indústria bélica brasileira. Exportação de armamentos, promoção comercial e diplomacia econômica estavam intimamente ligadas. No entanto, o Brasil não estabeleceria com o Iraque uma simples troca de armas por petróleo, com o intuito de obter apenas vantagem financeira.

Incluía-se, ao lado disso, um forte componente estratégico, com interesses claros, concretos e de prazo mais alongado. O Iraque representaria para a indústria bélica nacional um nicho adequado para o seu desenvolvimento. Isso porque o Iraque oferecia um mercado para a venda de produtos que, apesar de o Brasil possuir potencial para produzi-los, sem um parceiro externo, tornarse-ia inviável sua fabricação diante da necessidade de fazê-la em larga escala e da reduzida demanda interna. Em outras palavras, as características especiais da indústria bélica determinavam que seu desenvolvimento, em escala eficiente de competitividade, só seria possível se exportasse para mercados mais extensos que o aberto pelas encomendas internas. Do lado iraquiano, o governo de Saddam Hussein procurava diversificar seus fornecedores de equipamentos bélicos, por motivos de risco político que comprometesse sua estratégia, o que beneficiou as vendas de armas brasileiras àquele mercado. Com o tempo, o Brasil passaria da condição de importador de armamento para fornecedor da maior parte de suas necessidades domésticas e exportador de volumes substanciais para inúmeros países, figurando entre os dez maiores exportadores na década de 80 .

26 WENDT, Alexander. Social Theory of International Politics. Cambridge: University Press, 2004. p. 36. 
Da mesma forma como ocorrera na exportação dos demais bens e serviços brasileiros para o Iraque, o Estado associou-se ao setor privado. A diferença era que os bens de utilização militar eram considerados de "interesse nacional" e o monitoramento e a interferência do governo brasileiro nas negociações, em razão disso, eram sobremaneira maiores. ${ }^{27}$

Foi durante a Guerra Irã-Iraque que o relacionamento brasileiro-iraquiano verificou um de seus períodos mais intensos. Apesar das evidências em contrário, o governo brasileiro afirmava que não estava vendendo armas ao Iraque durante a guerra contra o Irã por causa de novos contratos, mas sim em decorrência de compromissos estabelecidos em programas de longo prazo e assinados entre o Brasil e o Iraque antes da eclosão do conflito. A mesma justificativa seria dada pelo Itamaraty tanto sob a gestão João Figueiredo/Saraiva Guerreiro, como sob a gestão José Sarney/Abreu Sodré. ${ }^{28}$

Os números quanto às vendas de armas pelo Brasil ao Iraque permanecem secretos ainda, o que dificulta as investigaçôes. De acordo com algumas estimativas mais realistas, as vendas brasileiras de equipamentos de guerra para o Iraque alcançaram a cifra de US\$ 3 bilhões ao todo, sendo apenas parcialmente contabilizada pelas estatísticas oficiais. Para outros, o Brasil exportou, em média, 2 bilhôes por ano ou mais. ${ }^{29}$ Havia, na realidade, a adoção de um procedimento de "cosmetização" da balança comercial brasileira no que se referia a armamentos.

Outra área estratégica em que Brasil e Iraque cooperaram era a relativa ao desenvolvimento de tecnologias nucleares. Segundo alguns setores do governo em especial a partir da presidência de Figueiredo, mas avançando sem modificações visíveis para dentro do governo civil do presidente Sarney -, o desenvolvimento da tecnologia nuclear pelo Brasil atendia também a critérios estratégicos, além daqueles reservados ao programa nuclear energético de Angra. Nesse sentido, à margem do acordo nuclear firmado com a Alemanha em 1975/76, foi desenvolvido um programa nuclear paralelo pelo governo brasileiro, com finalidade militar - o "Programa Atômico de Tecnologia Nuclear". O objetivo final, provavelmente, era viabilizar a fabricação da bomba atômica pelo Brasil por meio da associação com um outro país.

Nisso, levando-se em conta que o Iraque pudesse deter o controle de algumas fases da tecnologia do processo nuclear e que estava também interessado em desenvolver sua capacidade nessa área, ele poderia representar um parceiro

27 MONTENEGRO, Marcelo Luis. Op. cit. pp. 8, 24 e 61.

28 GUERREIRO, Ramiro Saraiva. Op. cit. p. 180. VIZENTINI, Paulo G. F. Op. cit. p. 333. Chanceler do Iraque vem discutir intercâmbio e a questão palestina. Gazeta Mercantil. 02/05/1988. Ministro do Iraque vem ver o apoio do Brasil. Jornal do Brasil. 30/04/1988. BRASIL. Ministério das Relaçóes Exteriores. Resenha de Política Exterior do Brasil. N. 42, julho/set. de 1984. A conferência do chanceler Saraiva Guerreiro na Escola Superior de Guerra. Conferência de 31 de agosto de 1984.

29 A negra história das relações entre Brasil e Iraque. Jornal do Brasil. 12/08/1990. MONTENEGRO, Marcelo Luis. Op. cit. p. 65. 
ideal para o Brasil. Ademais, o Brasil esperava, com isso, incorporar tecnologia e treinamento de recursos humanos no setor nuclear por meio do triângulo que se formaria do Iraque com terceiras potências nucleares, como França e URSS. A conexão Brasil-Iraque na área nuclear apontava para uma cooperação promissora para ambos os países. Seriam, portanto, os objetivos militares e estratégicos de cada país, principalmente, que os levariam a cooperar na sensível área de desenvolvimento nuclear.

Apesar do caráter pacifista do acordo nuclear entre os dois países, assinado em 1980, alguns setores da imprensa davam conta da existência de um contrato, com fins militares, de fornecimento de urânio pelo Brasil ao Iraque de quase uma centena de toneladas. As autoridades de ambos os países negavam a informação. De fato, o Brasil não poderia fornecer urânio ao Iraque e daí, simples e diretamente, construir uma bomba. A ligação não seria do tipo tudo (fornecer urânio altamente enriquecido) ou nada (fornecer apenas urânio natural ou levemente enriquecido). ${ }^{30}$ Não é possível ser categórico, mas os indícios apontam que o Brasil forneceu urânio ao Iraque com fins militares e que o Estado brasileiro tinha plena consciência disso. Afinal, entre o urânio natural (yellow cake), o levemente enriquecido e o enriquecido, existem outros estágios de enriquecimento, que, caso fosse descoberto o seu fornecimento ao Iraque, ficaria claro que o Brasil estava colaborando com aquele país para a construção da bomba e, portanto, para fins não-pacíficos, fato que as autoridades brasileiras temiam. Até mesmo o expressivo quantitativo de urânio fornecido, seja natural ou enriquecido, poderia levantar suspeitas. Daí a razão de eventuais embarques de urânio deverem ser secretos.

De qualquer maneira, a cooperação nuclear entre Brasil e Iraque não preocupava a Agência Internacional de Energia Atômica (AIEA) até os primeiros anos da década de 1980, mesmo não sendo o Brasil um membro do TNP (Tratado de Não-Proliferação Nuclear). Apesar das diversas acusações sobre programas clandestinos, tanto no Brasil quanto no Iraque, partidas de diferentes setores, os responsáveis pela formulação e aplicação de medidas de segurança da AIEA consideravam que não havia qualquer motivo para alarme, seja no caso brasileiro, seja no iraquiano. A principal razão: o ainda relativamente baixo desenvolvimento de tecnologia nuclear nos dois países. O fato é que, para ser mais exato, Brasil e Iraque não estavam capacitados tecnologicamente para construir uma bomba atômica, mas trabalhavam e investiam intensamente (principalmente o Iraque) nos primeiros passos para tanto.

Em termos gerais, portanto, foi no governo Figueiredo que as relações do Brasil com o Iraque assumiriam um caráter fortemente militarista, o que seria herdado, em grande medida, pela administração Sarney. A nomeação de embaixadores-generais para o posto de Bagdá - Samuel Alves Correa e Alacyr

30 Ligações Perigosas. Veja. 24/06/1981. 
Frederico Werner - apontava para isso, que incluía planos na área de venda de armas e, principalmente, na área nuclear. Desse modo, "Iraque" se tornaria um assunto muito mais de "segurança nacional", de Estado-Maior das Forças Armadas, do que do Itamaraty. ${ }^{31}$ Depois dos dois generais, o governo brasileiro enviou um diplomata de carreira para a embaixada do Brasil em Bagdá. O encerramento da participação de militares na relação estratégica com o Iraque marcava, também, uma certa desaceleração na cooperação nuclear entre os dois países, mas sem quaisquer prejuízos no que se referia à venda de armas. ${ }^{32}$

\section{Declínio do relacionamento brasileiro-iraquiano}

Muito provavelmente, com a segunda crise energética, de 1979, o Brasil sem o Iraque teria enfrentado um grande colapso no abastecimento de petróleo. Contudo, a partir de meados da década de 1980, o País reduziu sensivelmente sua dependência das importações de petróleo do Oriente Médio, incluindo o Iraque. Ao lado disso, a capacidade financeira do Iraque via-se cada vez mais debilitada, o que, naturalmente, levou o Brasil a diminuir seus interesses no relacionamento com o país. Apesar disso, a diplomacia brasileira procurava manter no mesmo ritmo o seu interesse no Iraque, esperando obter novos contratos de investimentos e aumento nas importaçóes de produtos brasileiros. Ademais, se o Brasil não precisava tanto do petróleo importado como no passado, isso não significava que ele não dependia em grau expressivo do produto vindo de fora. O Iraque, enfim, continuava um importante fornecedor de petróleo e um dos principais exportadores do País. Mas, definitivamente, perdia importância para o Brasil. ${ }^{33}$

Em 1984/1985, o Brasil produzia cerca de 60\% do petróleo que consumia, enquanto que em 1978 esse número representava apenas 10\% do total. Além disso, o preço do petróleo importado, embora continuasse representando um ônus muito grande ao País, estava diminuindo rapidamente. De 1985 para 1986, os preços do barril de petróleo decaíram em quase 55\%, dos US\$ 28 para US\$13, se estabilizando nesse valor nos anos posteriores, em decorrência, principalmente, do excesso de oferta. Por esses motivos, o peso relativo do petróleo no total das importações do Brasil decaiu do patamar de mais de 50\% no início da década de 1980 para pouco mais de 20\% no fim da década. Em valores, os dispêndios com o petróleo importado em 1988 representavam cerca de 1/3 daquele do início da década. Outro ponto é que ficava mais fácil pagar pelo petróleo importado,

31 A negra história das relaçôes entre Brasil e Iraque. Jornal do Brasil. 12/08/1990. Brasil e Iraque: casório em crise. Jornal do Brasil. 9/08/1990.

32 Diplomata vai assumir a embaixada no Iraque. Estado de São Paulo. 12/01/1984. Werner designado para a embaixada no Iraque. Folha de São Paulo. 21/01/1983. Ligaçōes Perigosas. Veja. 24/06/1981.

33 BRASIL. Ministério das Relaçôes Exteriores. Resenha de Politica Exterior do Brasil. N. 49, abril/junho de 1986. Abreu Sodré, na Escola Superior de Guerra: atividade diplomática exige diálogo. Palestra de 27 de junho de 1986. MENDES, Murillo e ATTUCH, Leonardo. Op. cit. p. 227. SAKAI, Keiko. Op. cit. p. 119. 
uma vez que a percentagem do total da importação de petróleo sobre o total das exportaçôes brasileiras decaiu de mais de 50\%, no início da década de 80, para apenas $10 \%$ nos seus últimos anos. O Brasil se tornaria, pois, menos vulnerável às oscilaçōes no mercado internacional do petróleo. ${ }^{34}$

Paralelamente, o governo brasileiro adotou uma efetiva política de diversificação de fornecedores de petróleo. Em outros termos, o discurso observado ao longo da década de 1970 de que era premente a busca por novos fornecedores só seria implementado de fato a partir da segunda metade da década de 1980, canalizando maior volume de importações para países como Venezuela, México, Angola e China. O Iraque, nesse contexto, perdia cada vez mais seu peso relativo nos cálculos da engenharia diplomática brasileira. ${ }^{35}$

$\mathrm{Na}$ ocasião da invasão do Kuwait, o problema do abastecimento de petróleo não era mais tão dramático quanto nos casos anteriores de crises políticas no Oriente Médio. As chances do surgimento de uma nova crise do petróleo eram remotas. Além de o Brasil estar menos dependente do petróleo importado, não faltavam fornecedores alternativos no mercado internacional. O governo brasileiro se sentia, assim, livre para, sem grandes custos à economia do País, se distanciar da posição iraquiana, o que facilitava a execução de uma clivagem desde o início proposta por Fernando Collor/Francisco Rezek em relação às gestôes anteriores, em que eram observados "alinhamentos automáticos" com os fornecedores de petróleo. Os antigos temores das autoridades brasileiras em relação à instabilidade política no Oriente Médio e um eventual corte no fornecimento de petróleo ao País ficaram no passado. ${ }^{36} \mathrm{O}$ Iraque sem o fascínio do petróleo - tanto da parte de seu fornecimento como dos recursos financeiros criados pela sua exploração interessava cada vez menos ao Brasil.

Logo em seguida à invasão do Kuwait pelo Iraque, os EUA iniciaram uma campanha de demonização de Saddam, em que era preciso "deter o avanço do mal”. Para George Bush, o Iraque estava separado do mundo civilizado por séculos. Isso significava o oposto daquilo que o presidente Fernando Collor planejava para o Brasil. A exemplo do que fizera o Japão e outros aliados dos norte-americanos, o Brasil começava, então, a pautar sua política externa para o Oriente Médio, principalmente, em torno da órbita dos EUA, a fim de agradálos. ${ }^{37}$ Em termos pragmáticos, era necessário, então, para a diplomacia brasileira,

34 SKIDMORE, Thomas. Op. cit. p. 529. RELATÓRIO Banco Central do Brasil, 1983 e 1988. ALMANAQUE Abril, 1987. FAUSTO, Boris. Op. cit. p. 279. BRASIL. Ministério das Relações Exteriores. Resenha de Politica Exterior do Brasil. N. 42, julho/set. de 1984. A conferência do chanceler Saraiva Guerreiro na Escola Superior de Guerra. Conferência de 31 de agosto de 1984.

35 Arquivo Histórico do Itamaraty (AHI), Brasília, Embaixada em Bagdá para Secretaria de Estado. Confidencial. Em 03/01/1985. Brasil-Iraque: a razão volta a prevalecer. Gazeta Mercantil. 19/01/1984.

36 Sanção econômica ao Iraque. Correio Braziliense. 07/09/1990. Brasil e Iraque: casório em crise. Jornal do Brasil. 09/08/1990. Missão acerta hoje saída dos brasileiros. O Globo. 17/09/1990.

37 SAKAI, Keiko. Op. cit. p. 121. WENDT, Alexander. Op. cit. p. 342. 
fazer o caminho inverso daquele trilhado desde princípios da década de 1970, formulado também de forma pragmática, ou seja, distanciando-se o mais rápido possível de um país considerado pária pelo sistema internacional. Nesse ponto, o relacionamento brasileiro-iraquiano confirma a tese de que a estrutura e a posição que um país ocupa nela são fundamentais, ao lado da política doméstica, para explicar importantes movimentos da política externa de um país.

Após a invasão do Kuwait, prevendo um desenlace violento para o problema, o governo do Brasil procurou intensificar as gestôes no sentido de retirar todos os cidadãos brasileiros do território iraquiano sob risco de conflito militar. No entanto, a concessão de vistos de saída havia sido suspensa pelo Conselho Revolucionário iraquiano. Diante disso, o foco da diplomacia do Brasil passou a ser a libertação dos reféns, que continuaria até o seu desfecho em outubro de 1990, pela Missão Paulo Tarso Flecha de Lima. O número estimado de brasileiros era de 450, ou seja, muito menos dos cerca de 5.000 que viviam no Iraque em meados da década de $1980 .^{38}$

Os ataques ao Iraque empreendidos pela aliança composta por trinta e dois Estados, liderados pelos Estados Unidos da América, acabaram com a derrota total do país. Após a Guerra do Golfo, o Iraque sofreria severo embargo comercial sob o auspício da ONU, efetivando sua condição de país falido e representando, em definitivo, o fim de uma fase nas suas relações com o Brasil. ${ }^{39}$ Ocorria, portanto, uma reacomodação da política externa brasileira para o Iraque, em função de uma nova realidade doméstica e, principalmente, externa-estrutural. As relações BrasilIraque conheceriam com esse episódio um novo estágio, que marcaria, ao menos por alguns anos, a sua suspensão completa. A situação de antes de 1971 entre os dois países, em que o grau de relacionamento era próximo a nulo, retornaria trinta anos depois.

Depois da invasão liderada pelos EUA em 2003, é difícil apontar precisamente o novo papel do Brasil no Iraque sob a dominação norte-americana. Sem embargo, a retomada das relações comerciais e políticas entre os dois países depende, agora, dos desenvolvimentos da intervenção dos EUA. A invasão do Iraque de 2003, juntamente com a suspensão do embargo comercial contra o país, poderá significar o surgimento de uma nova fase no relacionamento brasileiroiraquiano, mas em condiçóes absolutamente diversas daquelas do passado, em que foi considerada "especial". Ademais, o Iraque mergulharia em um verdadeiro turbilhão de violência, em que as mortes de civis tornar-se-iam banalizadas.

38 Iraque retém brasileiros que conhecem segredo militar. Jornal do Brasil. 23/08/1990. Brasileiro pode estar ligado a míssel. Gazeta Mercantil. 23/08/1990. Caminho minado: o conflito armado pelo Iraque impede a Mendes Júnior de conquistar US\$ 6 bilhōes em novos contratos. IstoÉ Senhor. 05/09/1990. MENDES, Murillo e ATTUCH, Leonardo. Op. cit. pp. 220 e 221.

39 MENDES, Murillo e ATTUCH, Leonardo. Op. cit. p. 219. ABDULLAH, Thabit A J. A Short History of Iraq. London: Pearson Longman, 2003. 197. 
Se comparado ao Iraque da década de 1970 e, principalmente, com o que ele pretendia se tornar, o país havia retrocedido de forma colossal.

\section{Conclusão}

As relações entre o Brasil e o Iraque figuram-se como um capítulo especial da história recente da política externa brasileira. Se atualmente a importância do Iraque para o Brasil é reduzida, no passado, mormente nos primeiros anos da década de 1980, a posição do país árabe, em termos de economia e de estratégia militar, era bastante diversa. Nesse aspecto, o petróleo determinou a história do relacionamento entre os dois países, mas não a limitou apenas às compras e vendas do produto.

O Iraque representou para o Brasil uma oportunidade em pelo menos dois aspectos: i) fornecimento de petróleo a preços oficiais, mesmo em tempos de crise no mercado internacional; e ii) mercado consumidor para exportações de produtos e serviços brasileiros. Isso porque o Iraque era um Estado altamente revisionista e, portanto, isolado, o que significava um importante espaço livre de atuação da diplomacia brasileira junto a um produtor de petróleo. Com o tempo, o Iraque receberia atenção privilegiada por parte da diplomacia, da Petrobras e dos demais órgãos do governo.

Em muitos momentos, a despeito de uma resistência do Itamaraty, que preferia concentrar a agenda bilateral em assuntos econômicos, os interesses iraquianos eram principalmente políticos. Não havia uma dissociação clara entre economia e política da parte do Iraque. Nesse aspecto, por exemplo, a questão palestina para o Brasil foi sensivelmente influenciada pelo seu relacionamento com o Iraque.

Em poucas palavras, nem os déficits comerciais contra o País nem as pendências das dívidas iraquianas (com empresas e o governo brasileiros) são capazes de indicar, isoladamente, se o relacionamento econômico entre os dois países foi prejudicial ou lucrativo ao Brasil. Levando-se em consideração a importância estratégica do petróleo importado para a economia brasileira e comparando com o que ocorreu com os demais países do Oriente Médio, o relacionamento brasileiro-iraquiano trouxe substanciais dividendos para o Brasil, contribuindo para o seu objetivo de complementação do desenvolvimento econômico pela política externa. Para se chegar a um balanço do relacionamento, deve-se levar em consideração, portanto, um contexto estratégico e econômico mais amplo.

Recebido em 15 de agosto de 2007 Aprovado em 30 de novembro de 2007 


\section{Resumo}

No artigo se propõe analisar as relações entre o Brasil e o Iraque, com ênfase no período de 1973 a 2007. Para tanto, são examinados os aspectos econômicos, políticos e estratégicos do relacionamento bilateral, passando pelos dois choques do petróleo, a Guerra do Golfo e, finalmente, a ocupação do Iraque em 2003.

\section{Abstract}

This article aims to analyze the Brazil-Iraq relations, from 1973 to 2007. For this purpose, the economic, political and strategic aspects of the bilateral relations were examined, including the 1973 and the 1979 oil crisis, the Persian Gulf War and, finally, the US-led invasion of Iraq, in 2003.

Palavras-chave: Brasil, Iraque, política externa brasileira, petróleo, Oriente Médio.

Key words: Brazil, Iraq, Brazilian foreign policy, oil, Middle East. 